\title{
The Enhanced Cognitive Interview: towards a better use and understanding of this procedure
}

\author{
Rui M. Paulo $\ddagger$, Pedro B. Albuquerque ${ }^{\dagger}$ and Ray Bull ${ }^{\S}$ \\ $\ddagger$ (Corresponding author) School of Psychology - University of Minho, Campus de Gualtar, \\ 4710-057 Braga, Portugal. Tel: +351 253604 220; email: id4299@alunos.uminho.pt \\ †School of Psychology - University of Minho, Braga, Portugal \\ $\S$ School of Law and Criminology, University of Derby, Derby, UK \\ Submitted 11 October 2013; accepted 15 November 2013 \\ Keywords: enhanced cognitive interview, police interviewing, witness \\ interviewing
}

Rui Paulo is a PhD student at the Department of Basic Psychology, School of Psychology - University of Minho, as well as a visiting research assistant at the Department of Psychology, University of Portsmouth. His PhD project is being funded by the Foundation for Science and Technology (FCT). In 2012, he obtained his masters degree in psychology. His major research topic is investigative interviewing. $\mathrm{He}$ has attended and published several papers and posters at scientific conference proceedings.

Pedro B. Albuquerque is professor at the School of Psychology - University of Minho (Portugal). After completing his PhD at the University of Minho, he created the Research Group for Human Memory which is devoted to the development of knowledge about human memory, namely the production of false memories through the Deese-Roediger-McDermott (DRM) paradigm and procedures that enhance eyewitness memory. He has published several papers in scientific journals and has experience in master's and PhD supervision.

Ray Bull is professor of criminal investigation at the University of Derby and visiting Professor at Portsmouth University. In 2012 he was elected

International Journal of Police Science and Management, Vol. 15 No. 3, 2013, pp. 190-199. DOI: $10.1350 /$ ijps.2013.15.3.311
'President-Elect' of the European Association of Psychology and Law. In 2010, he became an honorary fellow of the British Psychological
Society (restricted to 40 living psychologists). He received the 'Award for Life-time Contribution to Psychology and Law' from the European Association of Psychology and Law in 2008 and a Commendation from the London Metropolitan Police in 2005.

\section{Abstract}

The Enhanced Cognitive Interview is accepted as one of the most successful techniques for enhancing witness recollection. This type of interview has been studied all over the world (eg, Europe or the USA) and is used by police officers in many different countries (eg, the UK and New Zealand). Nonetheless, it is essential for police officers to understand how, and when, to properly apply this interview. Therefore, we examined the underlying psychological processes involved in this interview, and what research can tells us about the situations and purposes that can benefit from applying it.

\section{INTRODUCTION}

During police and forensic investigations, interviewing witnesses is often a key procedure that frequently determines the outcome of the investigation (Milne, 1997). 
However, what witnesses report rarely fully corresponds with what they remember. The commonly used questioning techniques may produce a reduced amount of valuable information, as well as some incorrect information. To manage this difficulty, Geiselman et al. (1984) developed the Cognitive Interview, which is now commonly accepted as one of the most successful procedures for enhancing witness recollection. Studies have repeatedly demonstrated that this technique is able to increase the amount of correct information recalled by witnesses, while maintaining accuracy (eg, Campos \& Alonso-Quecuty, 2008; Centofanti \& Reece, 2006; Dando, Wilcock, Milne, \& Henry, 2009; Davis, McMahon, \& Greenwood, 2005; Gwyer \& Clifford, 1997; Verkampt \& Ginet, 2010).

\section{WHAT IS THE COGNITIVE INTERVIEW?}

When first developed, the Cognitive Interview comprised four classic retrieval mnemonic instructions drawn from theoretical principles regarding human memory: report everything; context reinstatement; change perspective; and change order (Geiselman et al., 1984).

The report everything mnemonic consists of instructing witnesses to report everything they can remember, whether it seems trivial, or not (Fisher \& Geiselman, 2010). Allowing witnesses to talk freely about everything they remember is an important procedure because they typically choose to recall only information that they think may be important for the investigation. Nonetheless, details that the witness considers to be irrelevant might be valuable for the investigation. Furthermore, since our memories of aspects of an event overlap, some recall, even though irrelevant, might activate other relevant recall. It is also important that interviewers try to avoid interrupting witnesses while they are recalling. Furthermore, interviewers should take notes of the relevant information reported by the witness because, as we see below, these annotations are very valuable when applying the other mnemonics.

The context reinstatement mnemonic consists of asking witnesses to mentally recreate the to-be-recalled event that occurred at the crime scene, as well as their physiological, cognitive and emotional states at the time of the event. This mnemonic derived from the premise that memory retrieval is more efficient when the context of the original event is recreated during recall (Tulving \& Thomson, 1973). Traditionally, this procedure was achieved by asking witnesses to close their eyes, or to look at a blank space in the interview room, and think about different moments of the crime. For that purpose, the interviewer should note each of the relevant episodes described by witnesses during their initial free report, and later fully explore each mental image with the witness. To facilitate context reinstatement, statements should be given in the past tense. However, over many years of research, several alternative procedures have been proposed. For instance, some authors propose using Sketch Mental Reinstatement of Context instead of the classical reinstatement of context mnemonic (Dando, Wilcock, Behnkle, \& Milne, 2011; Dando, Wilcock, \& Milne, 2009). When using this technique, witnesses draw the witnessed event themselves and then use that same sketch to describe what they experienced. This procedure allows witnesses to initiate their own contextual retrieval cues (eg, by drawing the crime scene), simplifying the context reinstatement task for both the interviewer and the witness. This sketching technique is also less time-consuming and free from interviewers' interference, since it is the witness who directs the context reinstatement task, and not the interviewer (eg, in the classical 
procedure, the interviewer could inadvertently use some misleading retrieval cues drawn from other witnesses' reports).

The change perspective technique consists of asking the witness to recall the event from a different perspective (eg, if they report from a frightened perspective, they might then be asked to change to the relaxed perspective they were in before they realised a crime was about to occur). Once again, the interviewer should use the witness's initial free report to later select which are the better perspectives to adopt. Since a different memory retrieval procedure is used for this mnemonic, reported information usually increases, particularly peripheral information (eg, other witnesses' behaviour during the crime).

Lastly, the change order mnemonic consists of asking the witness to now recall the event in a different order (eg, reverse order). With this technique, overlooked details might be remembered and recall accuracy usually increases. When recalling an event, people can be influenced by their prior knowledge and by their schemas or scripts (organised pattern of thoughts and behaviour) about that type of event (Griffiths \& Milne, 2010). Therefore, new information is understood and recalled based on prior knowledge. This is called script-guided retrieval and can result in limited elicited information due to the exclusion of information that does not fit the script. Witnesses frequently confuse what they actually saw with their stereotypical idea of that particular crime. For instance, a witness may say that the robber first assaulted the security guard, not because he did, but because that usually happens, for instance, in films. However, scripts are usually organised in chronological order, and recalling the crime event in another order minimises this problem, by going beyond scriptconsistent recall (Dando \& Milne, 2009). This procedure can also be important in helping to evaluate statement credibility and in detecting lies (Bembibre \& Higueras, 2011; Hernández-Fernaud \& AlonsoQuecuty, 1997). Using the change order mnemonic to increase cognitive load can be helpful in lie detection, since lying can be a cognitively demanding task that may be difficult to perform simultaneously with other demanding tasks, such as describing the event in reverse order (Vrij et al., 2008).

Even though the first version of the Cognitive Interview only included these four procedures, the importance of considering social and communication aspects of the interview, for instance, to increase witness comfort and well-being during the interview, has been established over the years (Colomb \& Ginet, 2012). Therefore, Fisher and Geiselman (1992) included such procedures in a subsequent version of the Cognitive Interview - the Enhanced Cognitive Interview. Several procedures such as witness-compatible questioning, transferring control of the interview to the witness, mental imagery and rapport building are included in this subsequent version.

The first procedure, rapport building, refers to establishing a proper and positive relation with the witness. To build rapport, the interviewer should take some time to present himself or herself and explain to the witness why he or she is at the interview. The interviewer should also explain fully what is going to happen during the interview and show signs of active listening (eg, saying 'uhm' or gesticulating as a way of transmitting understanding). Using the witness's name as a way of personalising the interview, as well as starting by asking simple questions in order to reduce witness anxiety, are also effective ways of building rapport. Non-verbal behaviour is also an important part of this aspect, as well as an important part of the entire interview. The interviewer must always show interest in the witness and encourage him or her to recall more information. Also, the interviewer 
should behave in a way similar to that expected of the witness. For instance, if the interviewer is agitated, this is a problem, because it will unsettle the witness and have a negative impact on her or his recall abilities (Milne, 1997). Establishing rapport is not only essential when interviewing witnesses, but also when interviewing suspects (Read, Powell, Kebbell, \& Milne, 2009). In sum, rapport building not only contributes to witness well-being, it also increases the amount of recalled information, because, as we discussed further below, a calm and emotional secure witness is usually able to remember more crime details than a nervous and unsettled one.

The second procedure, transferring control of the interview to the witness, can be achieved by telling the witness that, even though the interviewer is there to help if needed, most of the work will be performed by the witness, because he or she is the one that has all the valuable information. Also, the interviewer should state to the witness that she or he has control over the production of information and, therefore, may stop whenever she or he wants and/or recount the information in which order he or she desires. By doing this, the interviewer is making sure that the witness feels more comfortable to talk about the event. Furthermore, the interviewer is no longer expected to ask all the important questions, since the witness knows that it is her or his task to report all the available information. This procedure allows witnesses to provide more information, and, as previously discussed, even though some of that information might be irrelevant for the investigation, it might activate other relevant recall that otherwise could not be accessed.

The third procedure, witness-compatible questioning, is achieved by asking the right questions at the right time. All the questions need to be compatible with the witness's retrieval pattern. As an example, if the witness starts to describe a bank robbery by telling the interviewer about how the robber left the bank, the interviewer should not simultaneously ask questions about how the robber entered the bank, because this would be interfering with the witness's retrieval path. Therefore, the interviewer must always conduct questions that are compatible with the information that the witness is describing at the moment, making it impossible for the interviewer to follow a strict interview protocol. The type of questioning conducted is also an important issue for the interviewer to consider. Closed questions (eg, forced choice questions) should always be avoided because they limit witnesses' response possibilities and produce incorrect information. For instance, if the interviewer asks the witness 'Did the robber have a knife or a gun?' this is not only implying that he or she already knows that the robber had a weapon (which can be a misleading question that may distort witnesses memory), as well as limiting witnesses' response possibilities (eg, maybe the witness thought that the robber had a baseball bat and will no longer feel comfortable to give that information). By contrast, open-ended questions (eg, 'Tell me about the robber') elicit more information and are also less suggestive (Guadagno \& Powell, 2009; Powell, Hughes-Scholes, Smith, \& Sharman, 2012). Questions in the negative form (eg, 'The robber didn't have a knife, did he?') and complex questions (eg, 'Describe the robber's clothes and the other witnesses' reaction to the crime') should also be avoided because witnesses can get confused and misinterpret these (Milne, 1997).

The last procedure, mental or guided imagery (Dando \& Milne, 2009), is very similar to the context reinstatement procedure, but, instead of asking the witness to recreate large-scale scenarios (eg, 'Think of the moment when the robber entered the 
bank'), the interviewer focuses on asking the witness to recreate more specific details (eg, 'Think about what the robber was wearing'). The use of several sensorial modalities is advised at this time because they activate different retrieval paths, therefore increasing the amount of recalled information (eg, 'What did you hear when the robber assaulted the security guard?').

Before finishing the interview, a summary and closure phase should be conducted. At the summary stage, the interviewer should recapitulate to the witness his or her interpretation of what has been recalled and tell the witness to feel free to correct any mistakes and add as much further information as possible. This increases not only report accuracy, but also the amount of recalled information. At the closure phase, the interviewer should minimise any emotional discomfort that the witness might be experiencing and show gratitude for witnesses' collaboration (partly in case the witness later wishes to add more recall).

Even though the previously described mnemonics and procedures have been found to be very important for enhancing witness recall, it is important to clarify that they should not be systematically used in all interviews. Each interview has its own specificities and the Enhanced Cognitive Interview is not an all-or-nothing approach. The interviewer must choose which strategies should be used at each interview, as well as what is the best time to use them. Even though Griffiths and Milne (2010) also support this flexibility notion, they suggest applying the Enhanced Cognitive Interview typically using the following structure:

1. greet and rapport;

2. explain the aims of the interview;

3. initiate a free report (using context reinstatement technique and openended questions);
4. questioning (using report everything and witness-compatible questioning);

5. varied and extensive retrieval (using different perspectives and temporal orders);

6. investigatively important questions (now the interviewer can introduce topics, even though the witness didn't yet mention these, if they are crucial for the investigation);

7. summary;

8. closure;

9. evaluation (evaluating obtained information and interviewers' performance).

In sum, in several countries, the Enhanced Cognitive Interview is becoming a widely used technique for enhancing witnesses' recollection that contains several mnemonics and procedures, derived from cognitive psychology theory, which enhance witnesses' memory. But what are exactly those theories and how can they contribute to memory enhancement? In the next section, we discuss how cognitive psychology theory underlying the Enhanced Cognitive Interview can contribute to the conducting of successful interviews.

\section{PSYCHOLOGICAL PROCESSES UNDERLYING THE ENHANCED COGNITIVE INTERVIEW}

When we memorise something, there are three major phases evolved: encoding, retention and retrieval (Baddeley, Eysenck, \& Anderson, 2009).

Encoding is the first step for creating a new memory. This phase occurs when we have initial contact with the information to be later recalled. In our daily lives, we describe this by saying we are trying to memorise something. However, encoding may not only be intentional (eg, when we try to memorise a telephone number for later use), but also incidental, for instance, 
when we see a street scuffle, although we might not purposely try to memorise its details, we later remember several details when told it resulted in a murder. Some people can be trained with regard to what information they should pay attention to during a crime (eg, bank employees). However, most witnesses are not expecting to observe a crime, therefore, they are not trained regarding what information to memorise.

The retention phase is the time between encoding and later trying to retrieve the information (eg, the time between memorising a telephone number, and trying to remember it to call someone). The longer this phase, the higher the probability of a person (eg, a witness) not finding it easy to recall the memorised information (eg, crime details) and for memory to be distorted (eg, to confuse what was seen with later information that was watched, for instance, on television). Therefore, unless the witness is very anxious after the crime and unable to be interviewed, police officers should try to interview the witness as soon as possible. However, it is frequently impossible to interview witnesses promptly. For instance, if there are too many witnesses for the number of police officers available, some will have to be interviewed days, or weeks later.

The last stage of human memory, the retrieval phase, occurs when we try to access an encoded and stored memory (eg, when witnesses try to remember what they saw at the crime scene). However, as previously discussed, what is retrieved does not always correspond to the encoded memories. Retrieved information is often only a small proportion of the encoded and stored information and can contain inaccurate details. To reduce such problems, and to enhance memory retrieval, we can use mnemonics. That is exactly what the Enhanced Cognitive Interview does. This type of interview instructs witnesses to use successful retrieval procedures that psychological studies (Tulving, 1991) have found to be useful, not only to increase the amount of information recalled, but also to prevent retrieval errors. The advantage of focusing on retrieval, as opposed to the encoding or retention phase, is that it can be enhanced after the episode occurred (eg, after witnessing a crime).

For the purpose of enhancing memory by aiding witnesses during their retrieval phase, the Enhanced Cognitive Interview uses the mnemonics described above, which are supported by two major theories about human memory (R. E. Holliday et al., 2011). The first is called the encoding specificity principle (Tulving \& Thomson, 1973) and states that memory is context dependant. Therefore, when the context of encoding is recreated at retrieval, the amount of elicited detail should increase. That is why the context reinstatement and mental imagery mnemonics are so important for conducting interviews and are included in the Enhanced Cognitive Interview.

The second theory is the multicomponent view of memory trace (Tulving, 1991), which states that memory is a network of associations and that the amount of coded information in storage is much higher than people can usually recall. Therefore, a memory may be accessed by using several different paths and different memory cues. By applying the report all, change order and change perspective mnemonics, the interviewer is guaranteeing that several retrieval paths are accessed and that the gap between encoded and retrieved information is reduced (Westera, Kebbell, \& Milne, 2011).

Now that we have briefly discussed the theory underlying the Enhanced Cognitive Interview, we address the research studies conducted to evaluate its utility. 


\section{RESEARCH STUDIES}

Various studies have demonstrated the efficacy of the Enhanced Cognitive Interview in several different countries (USA, UK, Australia, Brazil, etc.), with varying types of witness (children, adults and elderly adults), times between the crime and the interview (a few minutes to several days) and type of event (crime, accident, phone call, etc.), both in the laboratory and in the field (Colomb \& Ginet, 2012; R. Holliday, 2003; Mello \& Fisher, 1996; Öhman, Eriksson, \& Granhag, 2013; Stein \& Memon, 2006; Wright \& Holliday, 2007).

Laboratory studies are often conducted with university students. Usually, a video of a crime is presented to students who are then interviewed, by researchers, regarding the content of the video. Usually, one group of students is interviewed using a standard interview and another with the Enhanced Cognitive Interview. The amount, and accuracy, of recalled information in both groups is then compared. Field studies are very similar, but are conducted by police using real witnesses. The police officers are usually trained in applying a standard interview or the Enhanced Cognitive Interview. In both types of research (laboratory and field studies), researchers (Dando, Wilcock, Milne, \& Henry, 2009; Fisher \& Geiselman, 1992) have found that the group of participants interviewed using the Enhanced Cognitive Interview provides more valid information while maintaining accuracy.

Several studies have also concluded that the Enhanced Cognitive Interview is particularly efficient for recalling complex events (Geiselman, Fisher, MacKinnon, \& Holland, 1985). Most crimes are very complex events since they include, for instance, one or more offenders, several witnesses and different scenarios with lots of information units, such as the crime weapon, people's clothes and people's reactions.
Therefore, the Enhanced Cognitive Interview is particularly important for interviewing such witnesses.

Other studies (Mantwill \& Andres, 1990) have established that the Enhanced Cognitive Interview is more effective for enhancing episodic memory (eg, the recall of a crime episode) than semantic memory (eg, recalling studied information for an exam). Police officers and forensic psychologists are often interested in witnesses' episodic memory, because, as previously stated, the witness's report about the crime episode is one of the key aspects of most police investigations.

As stated above, this type of interview can be applied to people in different countries and of different ages. Interviewing children can be very demanding because the quality of children's reports is particularly dependant on the quality of the conducted investigative interview (London, 2001). The Enhanced Cognitive Interview can be used with children, and also seems to be efficient because the context reinstatement technique is particularly important for young children as they do not do this at all spontaneously. Similar results have been found for people with learning disabilities (Milne, 1997).

Other studies have found that this type of interview can also act as a protective factor against misleading post-event information (eg, if witnesses watch the television news regarding the crime before or between the interviews, their memory might be distorted). By using several retrieval paths and asking witnesses to tell the same story using different procedures and different sensorial modalities, the effect of misleading information can be reduced and report accuracy usually increases (R. Holliday, 2003; R. Holliday \& Albon, 2004; Memon, Holley, Wark, Bull, \& Köhnken, 1996).

Some studies (Fisher \& Geiselman, 2010; Walsh \& Bull, 2011) also state that the Enhanced Cognitive Interview might have 
an important role in promoting psychological health (eg, victims reported feeling more in control and confident after participating in this type of interview). Building and maintaining rapport (eg, by paying attention to witnesses' feelings) may also contribute to witnesses' psychological health. Even though one might think that witnesses' feelings are irrelevant for the judicial outcome of an interview, this factor may directly affect their recall. Therefore, promoting witnesses' well-being during the interview might increase the amount of recalled information and is also important if the witness needs to be interviewed again.

Finally, studies (Griffiths \& Milne, 2006; Griffiths, Milne, \& Cherryman, 2011) have evaluated whether the police training conducted in Britain, which includes teaching police officers cognitive questioning procedures, actually improved police officers performance when interviewing witnesses and suspects. Griffiths and colleagues concluded that police training improved the skills of the interviewers. However, refresher training is necessary because interview skills decline with time since training. Finally, Powell et al. (2012) argued that more experienced police officers who are used to using closed questions in their investigations, are usually more resistant to training regarding the use of proper openended questions (which is an important part of the Cognitive Interview). Therefore, additional effort must be made when training experienced police officers who are not used to conducting this type of interview.

\section{CONCLUSION}

The Enhanced Cognitive Interview is becoming ever more widely used as an interviewing technique that enhances witnesses' recollection by including several mnemonics and procedures derived from cognitive psychology theory. This type of interview is able to substantially increase the amount of information recalled by witnesses while maintaining accuracy. Furthermore, this interview can be used for different types of events (eg, different crimes), with different types of witnesses (eg, children and elderly adults), for different purposes (eg, enhancing recall and promoting well-being) and it is already used by police officers in several countries (eg, the UK and New Zealand). Bearing in mind that interviewing witnesses is usually a key procedure for most police and forensic investigations, we recommend the Enhanced Cognitive Interview procedure.

\section{FUNDING}

This work is partially funded by the Portuguese governmental institution 'Fundação para a Ciência e a Tecnologia' [grant number: SFRH/BD/84817/2012].

\section{References}

Baddeley, A. D., Eysenck, M. W., \& Anderson, M. C. (2009). Memory. New York: Psychology Press.

Bembibre, J., \& Higueras, L. (2011). Differential effectiveness of the cognitive interview in a simulation of testimony. Psychology, Crime \& Law, 17, 473-489.

Campos, L., \& Alonso-Quecuty, M. (2008). Language crimes and the cognitive interview: testing its efficacy in retrieving a conversational event. Applied Cognitive Psychology, 22, 1211-1227.

Centofanti, A. T., \& Reece, J. (2006). The cognitive interview and its effect on misleading postevent information. Psychology, Crime \& Law, 12, 669-683.

Colomb, C., \& Ginet, M. (2012). The Cognitive Interview for use with adults: an empirical test of an alternative mnemonic and of a partial protocol. Applied Cognitive Psychology, 26, 35-47.

Dando, C., \& Milne, R. (2009). The cognitive interview. In R. Kocsis (Ed.), Applied 
criminal psychology: A guide to forensic behavioural sciences (pp. 147-169). Sydney, NSW: Charles C. Thomas.

Dando, C., Wilcock, R., Behnkle, C., \& Milne, R. (2011). Modifying the cognitive interview: countenancing forensic application by enhancing practicability. Psychology, Crime \& Law, 17, 491-511.

Dando, C., Wilcock, R., \& Milne, R. (2009). The cognitive interview: the efficacy of a modified mental reinstatement of context procedure for frontline police investigators. Applied Cognitive Psychology, 23, 138-147.

Dando, C., Wilcock, R., Milne, R., \& Henry, L. (2009). A modified cognitive interview procedure for frontline police investigators. Applied Cognitive Psychology, 23, 698-716.

Davis, M., McMahon, M., \& Greenwood, K. (2005). The efficacy of mnemonic components of the cognitive interview: towards a shortened variant for time-critical investigations. Applied Cognitive Psychology, 19, 75-93.

Fisher, R. P., \& Geiselman, R. E. (1992). Memory-enhancing techniques for investigative interviewing: The cognitive interview. Springfield, IL: Charles C. Thomas.

Fisher, R. P., \& Geiselman, R. E. (2010). The Cognitive Interview method of conducting police interviews: eliciting extensive information and promoting therapeutic jurisprudence. International Journal of Law and Psychiatry, 33, 321-328.

Geiselman, R. E., Fisher, R. P., Firstenberg, I., Hutton, L., Sullivan, S. J., Avetissian, I. V., \& Prosk, A. L. (1984). Enhancement of eyewitness memory: an empirical evaluation of the cognitive interview. Journal of Police and Science Administration, 12, 74-80.

Geiselman, R. E., Fisher, R. P., MacKinnon, D. P., \& Holland, H. L. (1985). Eyewitness memory enhancement in the police interview: cognitive retrieval mnemonics versus hypnosis. Journal of Applied Psychology, 70, 401-412.

Griffiths, A., \& Milne, R. (2006). Will it all end in tiers? Police interviews with suspects in Britain. In T. Williamson (Ed.), Investigative interviewing: Rights, research, regulation (pp. 167-189). Portland, OR: Willan.

Griffiths, A., \& Milne, R. (2010). The application of cognitive interview techniques as part of an investigation. In C. A. Ireland \& J. M. Fisher (Eds.), Consultancy and advising in forensic practice: Empirical and pratical guidelines (pp. 71-90). Chichester, UK: BPS Blackwell.

Griffiths, A., Milne, B., \& Cherryman, J. (2011). A question of control? The formulation of suspect and witness interview question strategies by advanced interviewers. International Journal of Police Science \& Management, 13, 255-267.

Guadagno, B. L., \& Powell, M. B. (2009). A qualitative examination of police officers' questioning of children about repeated events. Police Practice and Research: An International Journal, 10, 61-73.

Gwyer, P., \& Clifford, R. (1997). The effects of the cognitive interview on recall, identification, confidence and the confidence/accuracy relationship. Applied Cognitive Psychology, 11, 121-145.

Holliday, R. (2003). The effect of a prior cognitive interview on children's acceptance of misinformation. Applied Cognitive Psychology, 17, 443-457.

Holliday, R., \& Albon, A. (2004). Minimising misinformation effects in young children with cognitive interview mnemonics. Applied Cognitive Psychology, 18, 263-281.

Holliday, R. E., Humphries, J. E., Milne, R., Memon, A., Houlder, L., Lyons, A., \& Bull, R. (2011). Reducing misinformation effects in older adults with cognitive interview mnemonics. Psychology and Aging, 27, 1191-1203.

Hernández-Fernaud, E., \& AlonsoQuecuty, M. (1997). The cognitive interview and lie detection: a new magnifying glass for Sherlock Holmes? Applied Cognitive Psychology, 11, 55-68.

London, K. (2001). Investigative interviews of children: a review of psychological research and implications for police practices. Police Quarterly, 4, 123-144.

Mantwill, M., \& Andres, J. (1990). Die wirkung des kognitiven interviews bei nicht-episodischem 
erinnerungsmaterial. (Unpublished manuscript). Universität Kiel, Kiel.

Mello, E., \& Fisher, R. P. (1996). Enhancing older adult eyewitness memory with the cognitive interview. Applied Cognitive Psychology, 10, 403-417.

Memon, A., Holley, A., Wark, L., Bull, R., \& Köhnken, G. (1996). Reducing suggestibility in child witness interviews. Applied Cognitive Psychology, 10, 503-518.

Milne, R. J. (1997). Analysis and application of the cognitive interview. (Unpublished doctoral dissertation). University of Portsmouth.

Öhman, L., Eriksson, A., \& Granhag, A. (2013). Enhancing adults' and children' earwitness memory: examining three types of interviews. Psychiatric, Psychology and Law, 20, 216-229.

Powell, M. B., Hughes-Scholes, C. H., Smith, R., \& Sharman, S. J. (2012). The relationship between investigative interviewing experience and open-ended question usage. Police Practice and Research: An International Journal. doi: 10.1080/15614263.2012.704170.

Read, J. M., Powell, M. B., Kebbell, M. R., \& Milne, R. (2009). Investigative interviewing of suspected sex offenders: a review of what constitutes best practice. International Journal of Police Science \& Management, 11, 442-459.

Stein, L. M., \& Memon, A. (2006). Testing the efficacy of the cognitive interview in a developing country. Applied Cognitive Psychology, 20, 597-605.
Tulving, E. (1991). Concepts of human memory. In L. R. Squire,

N. M. Weinberger, G. Lynch, \& J. L. McGaugh (Eds.), Memory: Organization and locus of change (pp. 3-32). New York: Oxford University Press.

Tulving, E., \& Thomson, D. (1973). Encoding specificity and retrieval processes in episodic memory. Psychological Review, 80, 352-373.

Verkampt, F., \& Ginet, M. (2010). Variations of the cognitive interview: which one is the most effective in enhancing children's testimonies? Applied Cognitive Psychology, 24, 1279-1296.

Vrij, A., Mann, S. A., Fisher, R. P., Leal, S., Milne, R., \& Bull, R. (2008). Increasing cognitive load to facilitate lie detection: the benefit of recalling an event in reverse order. Law and Human Behavior, 32, 253-265.

Walsh, D., \& Bull, R. (2011). Examining rapport in investigative interviews with suspects: does its building and maintenance work? Journal of Police and Criminal Psychology, 27, 73-84.

Westera, N. J., Kebbell, M. R., \& Milne, B. (2011). Interviewing witnesses: do investigative and evidential requirements concur? The British Journal of Forensic Practice, 13, 103-113.

Wright, A., \& Holliday, R. (2007). Enhancing the recall of young, young-old and old-old adults with cognitive interviews. Applied Cognitive Psychology, 21, 19-43. 